\title{
Effect of sawdust amendment on mineralization of organic nitrogen in a 2,4,5-trichlorophenol contaminated soil
}

\author{
D. Bello ${ }^{1 *} ;$ C. Trasar-Cepeda ${ }^{1} ;$ M.C. Leirós ${ }^{2}$ and F. Gil-Sotres ${ }^{2}$.

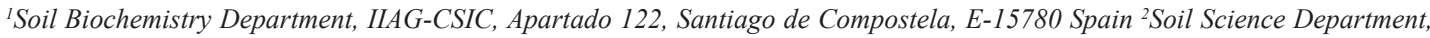 \\ Facultad de Farmacia, University of Santiago de Compostela, Santiago de Compostela, E-15782 Spain* Corresponding author. \\ e-mail: dibecum@iiag.csic.es
}

\begin{abstract}
Previous studies have demonstrated that the toxic effects of 2,4,5- trichlorophenol (2,4,5-TCP) are greater in agricultural soils than in forest soils; therefore these effects appear to be influenced by the total $\mathrm{C}$ content and soil $\mathrm{pH}$. Agricultural soils (usually low in organic C) contaminated with 2,4,5-TCP may be able to be remediated by the addition of organic waste products. To test this hypothesis, an agricultural soil was artificially contaminated with $5000 \mathrm{mg} \mathrm{kg}{ }^{-1}, 500$ times the Generic Reference Level (GRL) of 2,4,5-TCP, then pine sawdust was added to the contaminated soil at doses equivalent to $5 \%$ and $10 \%$ of the soil weight. The effect of the sawdust on the toxicity of the contaminant was studied by measuring the degree of mineralization of the organic nitrogen in the soil. The addition of 2,4,5-TCP produced a large increase in the amount of inorganic $\mathrm{N}$ present (basically ammoniacal forms), which suggests that the 2,4,5-trichlorophenol caused the death of a large part of the edaphic microbiota. The addition of sawdust buffered this effect, particularly at the highest dose $(10 \%)$ as the degree of mineralization was similar to that observed in the control sample treated with the same amount of sawdust, this indicating that $10 \%$ dose of sawdust is capable of mitigating the toxic effects of 2,4,5-TCP.
\end{abstract}

Keywords: 2,4,5-trichlorophenol, nitrogen mineralization, sawdust, soil contamination, soil remediation

\section{Introduction}

It has recently been shown that the degree to which acidic soils are affected by $2,4,5$ trichlorophenol $(2,4,5-$ TCP) clearly depends on land use, with the effects of this compound being greater in agricultural than in forest soils (Bello et al., 2008). The effect of land use has been interpreted in relation to two soil properties: organic matter content and $\mathrm{pH}$, and it has been found that the higher the $\mathrm{pH}$ (as in agricultural soils compared with forest soils), the greater the effect on the soil, and that the higher the organic matter content (as in forest soils compared with agricultural soils), the less the soil will be affected. In other words, the results reported by Bello et al. (2008) suggest that modification of these two properties is a potential method of remediating soils contaminated with 2,4,5-TCP, either by acidifying the soil or by increasing its organic matter content. 
Given that agricultural soils are more sensitive to the effects of the 2,4,5-TCP and that a decrease in the $\mathrm{pH}$ of these soils would strongly affect the productivity, the best option for remediation would be to increase the soil organic matter content, preferably by the addition of organic waste products. Pine sawdust is cheap and abundant in forest areas where 2,4,5TCP is widely used as a fungicide on sawn timber. The aim of the present study was to test the extent to which sawdust may protect the edaphic microbiota against the toxic effects of 2,4,5-TCP. The nitrogen mineralization potential was considered a diagnostic property as it readily enables determination of the effects of the contaminant on the edaphic microbiota. In addition, highly sensitive populations of microbes, such as nitrifying bacteria, are involved in nitrogen mineralization processes, and therefore any changes may provide additional information about the possible protective effects on sawdust over these microorganisms.

\section{Material and Methods}

The Ap horizon $(0-15 \mathrm{~cm})$ of a soil developed on granite and located at an altitude of $300 \mathrm{~m}$, in the surroundings of Santiago de Compostela (Galicia, NW Spain), was used in the present study. The soil was a Regosol (ISSS Working Group R.B.) cropped with maize. The pine sawdust (P. pinaster Ait.) used as a potential remediating agent was obtained from a local sawmill. The sawdust was sterilized, washed several times with distilled water, dried at $60{ }^{\circ} \mathrm{C}$ and then sieved to obtain the $<0.5 \mathrm{~mm}$ fraction. The $\mathrm{pH}$ in water of this fraction was 6.60 , and the total $\mathrm{C}$ and $\mathrm{N}$ contents were $53.80 \%$ and $0.04 \%$, respectively.

The soil was sieved in the laboratory $(<4 \mathrm{~mm})$ and an aliquot was artificially contaminated with $5000 \mathrm{mg}$ $\mathrm{kg}^{-1}$ of 2,4,5-TCP. This concentration represents 500 times the Generic Reference Level (GRL) for this product, as indicated by Spanish Legislation (Real Decreto 9/2005), and therefore the soil was strongly contaminated (a soil is considered contaminated when the level of contamination is more than 100 times the GRL). Given the low solubility of 2,4,5-TCP in water, it was first mixed with washed quartz sand (diameter $0.25-0.30 \mathrm{~mm}$ ), and then the mixture was shaken in a rotary shaker for 48 hours to homogenize it (Moscoso et al., 2007). Afterwards, the sand/contaminant mixture was added to each aliquot of soil (10 $\mathrm{g}$ of sand to $100 \mathrm{~g}$ dry soil). Control samples were also prepared by adding a similar quantity of sand without $2,4,5-\mathrm{TCP}$ to soil. Soil and sand (with or without 2,4,5-TCP) were manually mixed with a a rubber-coated glass stick until a homogeneous mixture was achieved.

Once the sand was added to the soil, aliquots $(500 \mathrm{~g})$ of both contaminated an uncontaminated soil were transferred to polypropylene containers and different doses of sawdust ( 0,5 and $10 \%$ of the dry soil weight) were added to each of these aliquots. The following samples were thus obtained: $\boldsymbol{C}_{\mathbf{0}}$ (uncontaminated soil without sawdust), $\boldsymbol{C}_{T C P}$ (contaminated soil without sawdust), $\boldsymbol{C}_{0}+\mathbf{5 \%}$ (uncontaminated soil plus $5 \%$ sawdust), $\boldsymbol{C}_{\circ}+\mathbf{1 0} \%$ (uncontaminated soil plus $10 \%$ sawdust), $C_{T C P}+5 \%$ (contaminated soil plus $5 \%$ sawdust), $C_{T C P}+10 \%$ (contaminated soil plus $10 \%$ sawdust). To all the soil samples the amount of distilled water required to maintain the samples at a moisture content of $80 \%$ field capacity (i.e. the water retained at $-33 \mathrm{kP}$ pressure), was added. The samples were prepared in triplicate and incubated at $25{ }^{\circ} \mathrm{C}$. Duplicate aliquots of each sample were removed at 0 , 2, 4, 7 and 15 days for determination of the different forms of inorganic nitrogen.

The inorganic $\mathrm{N}$ was extracted by shaking $10 \mathrm{~g}$ of soil with $50 \mathrm{ml}$ of $2 \mathrm{M} \mathrm{KCl}$ for 30 minutes in a rotary shaker. The suspensions were filtered through Whatman $\mathrm{n}^{\circ} 40$ filters and the filtrate was analyzed to determine the different forms of inorganic $\mathrm{N}$ present (total inorganic $\mathrm{N}$; ammoniacal $\mathrm{N}$ : $\mathrm{NH}_{4}^{+}$) by Kjeldhal distillation (Keeney and Nelson, 1982). The amount of nitrate $\mathrm{N}\left(\mathrm{NO}_{3}{ }^{-}\right)$was calculated as the difference between total inorganic $\mathrm{N}$ and ammoniacal $\mathrm{N}$, as different analysis with sulfamic acid during the Kjeldhal distillation indicate that nitrite 
$\mathrm{N}$ was not present in these soils (Keeney and Nelson, 1982). Extraction and determination of the nitrogen were carried out in duplicate, and the results for each sample and incubation time were therefore the mean values of 12 determinations ( 3 replicate incubations $\mathrm{x} 2$ replicate extractions x 2 replicate determinations). In all cases the results are expressed relative to soil dried at 105 (the weight of sand and/or sawdust in each sample was disregarded). Soil $\mathrm{pH}$ was determined in water (ratio 1:2.5), particle size distribution by Robinson's pipette method, total carbon by a modification of Sauerlandt's method, and total nitrogen by Kjeldahl's method (GuitiánOjea and Carballas, 1976). The location and general properties of the soil are listed in Tables 1 and 2 .

Table 1. Geographical characteristics of the used soil.

\begin{tabular}{ll}
\hline Soil type & Regosol \\
Situation & Santiago de Compostela, NW Spain \\
Longitude & $8^{\circ} 28^{\prime} 30^{\prime \prime} \mathrm{W}$ \\
Latitude & $42^{\circ} 57^{\prime} 20^{\prime \prime} \mathrm{N}$ \\
Altitude & 300 m.a.s.l. \\
Vegetation & Maize \\
Parent material & Granites \\
\hline
\end{tabular}

Table 2. General properties of the used soil.

\begin{tabular}{ll}
\hline $\mathbf{p H}$ \\
$\mathbf{H} 2 \mathrm{O}$ & 4.18 \\
$\mathbf{p H}$ & 3.67 \\
Total carbon $\left(\mathrm{g} \mathrm{kg}^{-1}\right)$ & 21.1 \\
Total nitrogen $\left(\mathrm{g} \mathrm{kg}^{-1}\right)$ & 1.9 \\
$\mathbf{C} / \mathbf{N}$ & 11 \\
Textural class & Sandy loam \\
Sand $\left(\mathrm{g} \mathrm{kg}^{-1}\right)$ & 640 \\
Silt $\left(\mathrm{g} \mathrm{kg}^{-1}\right)$ & 240 \\
Clay $\left(\mathrm{g} \mathrm{kg}^{-1}\right)$ & 120 \\
Olsen Inorganic P & $145 \mathrm{mg} \mathrm{kg}^{-1}$ \\
\hline
\end{tabular}




\section{Results and Discussion}

The behaviour observed in the uncontaminated control soil without sawdust (sample $\boldsymbol{C}_{o}$ ) during the incubation period was typical of agricultural soils in Galicia: strong initial nitrogen mineralization and later a trend towards stabilization (Trasar-Cepeda et al., 2008). A predominance of nitrate $\mathrm{N}$ was also observed, so that the ammoniacal $\mathrm{N}$ had almost disappeared by the end of the incubation period (Figure 1).
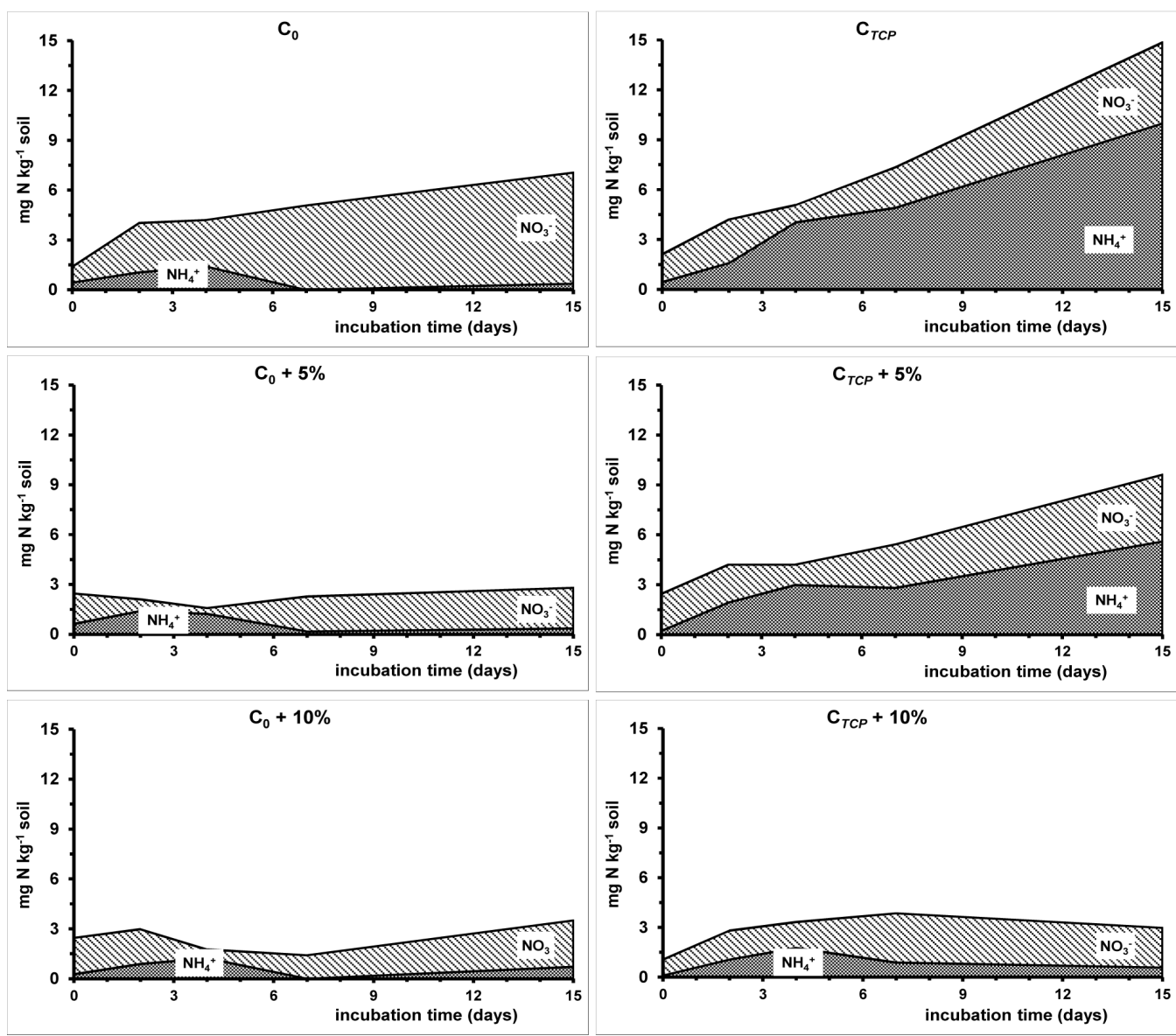

Figure 1. Quantities of ammonium- $\mathrm{N}\left(\mathrm{NH}_{4}^{+}\right.$, dark doted area) and nitrate- $\mathrm{N}\left(\mathrm{NO}_{3}^{-}\right.$, light striped area) mineralized for the different treatments throughout the incubation period. The sum of both forms of nitrogen is the total inorganic $\mathrm{N}$, i.e. the dark doted + light striped areas. 
The addition of 2,4,5-TCP to the soil (sample $\boldsymbol{C}_{T C P}$ ) strongly modified the nitrogen mineralization kinetics (Figure 1). Firstly, the total amount of $\mathrm{N}$ extracted increased greatly relative to sample $\boldsymbol{C}_{o}$, in direct relation to the incubation time. Secondly, the nitrate production tended to decrease throughout the incubation period (Figure 1). The increase in inorganic $\mathrm{N}$ must be attributed to the death of part of the edaphic microbiota caused by the 2,4,5-TCP (Bello et al., 2008). The cellular content of the dead microorganisms would have entered the soil solution and the surviving microorganisms would have been able to use this as a source of nutrients. Moreover, the lower relative presence of nitrate $\mathrm{N}$ (Figure 1) suggests that the nitrifying organisms were strongly affected. This is not surprising as several authors have reported that populations of nitrifying bacteria are highly sensitive to soil contamination (Dommergues and Mangenot, 1970). The presence of 2,4,5-TCP clearly affected the soil nitrogen cycle, and this effect should be annulled in any remediation process.

As sawdust is an organic product that possibly affects the soil nitrogen cycle, any of its effects must be established before the remediating potential of the product can be evaluated. The addition of both doses of sawdust to uncontaminated soil $\left(\boldsymbol{C}_{o}+\mathbf{5 \%}\right.$ and $\boldsymbol{C}_{o}$ $+10 \%)$ generated the typical "nitrogen hunger" effect (Jenny et al., 1946; Kumar and Goh, 2000) manifested by almost all of the mineralized nitrogen being used by soil microorganisms, thus preventing accumulation of the element (Figure 1). This effect occurred because sawdust contains very little nitrogen, therefore the soil microorganisms had to use any nitrogen that was available. However, and independently of the dose added, the addition of sawdust to the soil did not affect the nitrifying microorganisms, as in both treatments with sawdust there was generally more nitrate $\mathrm{N}$ than ammoniacal $\mathrm{N}$ (Figure 1), as also observed in the control sample $\left(\boldsymbol{C}_{\boldsymbol{o}}\right)$.

The effects of the application of sawdust to the soil contaminated with 2,4,5-TCP differed in relation to the dose added. With the lower dose $\left(\boldsymbol{C}_{T C P}+\mathbf{5 \%}\right)$ the nitrogen mineralization pattern was similar to that in the soil contaminated with $2,4,5-\mathrm{TCP}\left(\boldsymbol{C}_{T C P}\right)$ which suggests, as indicated above, that most of the nitrogen extracted from sample $\boldsymbol{C}_{T C P}+\mathbf{5 \%}$ originated from dead microorganisms (Figure 1). On the other hand, the distributions of ammoniacal $\mathrm{N}$ and nitrate $\mathrm{N}$ were similar to those in sample $\boldsymbol{C}_{T C P}$ throughout the incubation; the lower proportion of nitrates in relation to the total (compared to $\boldsymbol{C}_{\boldsymbol{0}}+\mathbf{5 \%}$ ) suggests that (as in this latter), the nitrifying microorganisms were greatly affected by the presence of 2,4,5-TCP. However, less nitrogen was mineralized, which may indicate that the number of microorganisms sensitive to the presence of the chlorophenol was lower. This dose of sawdust therefore may have a protective effect, although it may not totally counteract the effects of the contaminant. On the contrary, the results of the addition of the highest dose (sample $C_{T C P}+10 \%$ ) suggest that this dose of sawdust protected the soil much better from the action of the contaminant. Thus, with this treatment, the amount of inorganic nitrogen did not increase and a situation of nitrogen hunger was produced, similar to that observed in the uncontaminated soil to which $10 \%$ sawdust was added, sample $\boldsymbol{C}_{o}+\mathbf{1 0} \%$ (Figure 1 ). This indicated the presence of active populations of microorganisms that consumed most of the inorganic nitrogen released. There was also a predominance of nitrate $\mathrm{N}$ (Figure 1), indicating that the nitrifying populations were not affected, although these populations are extremely sensitive to contaminants, and that in treatment $\boldsymbol{C}_{T C P}$ they were affected by the addition of 2,4,5-TCP. This result confirms that the dose of $10 \%$ sawdust neutralized the action of 2,4,5TCP added to the soil.

The mechanism of protection possibly involves adsorption of 2,4,5-TCP on the sawdust particles, mainly via hydrophobic or van der Waals bonds (physical adsorption). Another possible mechanism, would be the adsorption via electrostatic bonds (chemical adsorption) between the anionic form of 2,4,5-TCP and positive charges that may be generated on the sawdust particles, possibly during the wood cutty process. In addition, this latter mechanism 
vía electrostatic bonds) would be feasible considering that the $\mathrm{pH}$ of the sawdust (6.60) is very close to the $\mathrm{p} K_{a}$ of dissociation of $2,4,5-\mathrm{TCP}(6.92 \pm 0.02$, Severtson and Banarjee 1996), which would facilitate dissociation of the phenolic group and the appearance of anionic forms.

\section{Conclusions}

The results of this study clearly demonstrate that pine sawdust neutralized the effect of 2,4,5-TCP on the edaphic microbiota that participates in nitrogen mineralization, possibly because of its high sorption capacity. However, the overall protective effect was only achieved with high doses of sawdust, as the effects of application of lower doses of sawdust were less clear. The need to use such high doses of sawdust, unpractical in field situations, limits the use of this product as a remediating agent for soils contaminated with 2,4,5-TCP. Other organic waste products that are capable of preventing the toxic effects of the compound are currently under investigation.

\section{Acknowledgements}

This study was financed by the Xunta de Galicia (Project No. 10PXIB203154PR) and the Spanish Ministerio de Ciencia e Innovación (Project No. CTM2011-25664). The authors thank Ana I. IglesiasTojo and Pablo Piñeiro-Mayán for assistance in carrying out the analyses.

\section{References}

Bello, D., Trasar-Cepeda, C., Leirós, M.C., GilSotres, F. 2008. Evaluation of various tests for the diagnosis of soil contamination by $2,4,5$ trichlorophenol (2,4,5-TCP). Environmental Pollution. 156, 611-617.
Czaplicka, M., 2004. Sources and transformations of chlorophenols in the natural environment. The Science of the Total Environment. 322, 21-39.

Dommergues, Y., Mangenot, F. 1970. Ecologie microbienne du sol. Masson Editorial, Paris, France

Guitián Ojea, F., Carballas, T. 1976. Técnicas de Análisis de Suelos. Pico Sacro Editorial, Santiago de Compostela, 288 p.

ISSS Working Group R.B. 1998. World Reference Base for Soil Resources: Introduction. International Society of Soil Science, International Soil Reference and Information Centre and Food and Agriculture Organization of the United Nations. Acco, Leuven.

Jenny, H., Adams, F., Arnon, D.I., Bodman, G.B., Broyer, T.C., Conrad, J.P., Kelley, W.P., Storie, R.E., Ulrich, A., Veihmeyer, F.J., Weir, W.W. 1946. Exploring the soils of California, in: Hutchison, C.B. (Ed.), California Agriculture, University of California Press, Berkeley, USA, pp: 317-394.

Keeney, D.R., Nelson, D.W., 1982. Nitrogen-Inorganic forms, in: Page, A.L. (Ed.), Methods of Soil Analysis, Part 2. Chemical and Microbiological Properties. SSSA, Madison, USA, pp: 643-698.

Kumar, K., Goh, K. 2000. Crop residues and management practices. Advances in Agronomy. 68, 197-319.

Moscoso, F., Bouzas, S., Gil-Sotres, F., Leirós, M.C., Trasar-Cepeda, C. 2007. Suitability of the OECD tests to estimate contamination with 2,4 dichlorophenol of soils from Galicia (NW Spain). The Science of the Total Environment. 378, 58-62.

Real Decreto 9/2005. Ministerio de la Presidencia (Gobierno de España), Boletín Oficial del Estado 8 Enero 2005, Madrid, pp: 1833-1843. 
Severtson, S.J., Banarjee, S. 1996. Sorption of chlorophenols to wood pulp. Environmental Science and Technology. 30, 1961-1969.
Trasar-Cepeda, C., Leirós, M.C., Seoane, S., GilSotres, F. 2008. Biochemical properties of soils under crop rotation. Applied Soil Ecology. 39, 133-143. 